$\begin{array}{ll}\text { Variants } & \begin{array}{l}\text { Variants } \\ \text { The Journal of the European Society for Textual } \\ \text { Scholarship }\end{array}\end{array}$

15-16 | 2021

Textual Scholarship in the Twenty-First Century

\title{
Editing for Man and Machine. Digital Scholarly Editions and their Users
}

\section{Anne Baillot and Anna Busch}

\section{(2) OpenEdition \\ Journals}

Electronic version

URL: https://journals.openedition.org/variants/1220

DOI: 10.4000/variants. 1220

ISSN: 1879-6095

\section{Publisher}

European Society for Textual Scholarship

\section{Printed version}

Date of publication: 1 July 2021

Number of pages: 175-187

ISSN: 1573-3084

\section{Electronic reference}

Anne Baillot and Anna Busch, "Editing for Man and Machine. Digital Scholarly Editions and their Users", Variants [Online], 15-16 | 2021, Online since 01 July 2021, connection on 16 July 2021. URL: http://journals.openedition.org/variants/1220 ; DOI: https://doi.org/10.4000/variants.1220 


\title{
Editing for Man and Machine. Digital Scholarly Editions and their Users
}

\author{
Anne Baillot and Anna Busch
}

\begin{abstract}
This article explores ways in which digital scholarly editions can reach new audiences by taking advantage of the computer-readability of their digital content. Based on the development work on the edition Briefe und Texte aus dem intellektuellen Berlin 1800-1830, we present different Open Access-based options that allow for interlinking datasets and facilitate the development of digital editions that go beyond what print editions can achieve on paper.
\end{abstract}

Digital SCHOLARLY EDITIONS of manuscripts oftentimes present themselves in the form of a scan of the manuscript on one side of the monitor and a transcription on the other side ${ }^{1}$ By presenting this view of the text, the edition caters to a specific way of reading. But the kind of information it conveys is - in spite of its apparent similarity - not the same as what print facsimile editions enable. Digital editions are compelled to establish the chronology of textual genesis (a linearity in the representation of text production made necessary by the text encoding), while a print facsimile edition is not necessarily bound to produce this kind of analysis. But although the encoding process suggests a more linear and in-depth approach to textual structure on this level, one can observe, on the other hand, a tendency not to render all glyphs and signs with the same precision. The reasons behind such editorial decisions are neither solely due to technical challenges (that would impede the digital reproduction of non-textual elements, for example) nor to a fundamentally lackadaisical consideration of non-textual elements. Instead, the editor starts from the assumption that the reader should be able to make the connection between the scan and the transcription, and cede to the fact that one is not identical to the other. In other words, the reader's understanding of the editorial setting is fundamental to the conception of all editorial decisions that underlie the edition's development.

The potential affordances of the digital medium affect our conception of textual structure on different levels. This offers editors of digital scholarly editions the opportunity to break away from the page format (see also the first chapter of Grafton 2012). Still, most editors stick to what they know, be that because of the format of the scans they acquired for the edition, or due to the lack of a

1 See for example: van Gogh 2009 $\mid$ Schlegel 2014 | Ghelardi|2019, or Jung 2015 For a catalog of digital scholarly editions consult Sahle 2008 or Franzini|2016 
persuasive alternative model that would be as easily accessible to readers (in terms of readability) as the familiar page is.

What is more, a digital edition is not just (and perhaps not even primarily) designed for humans to read in a linear way, but also to be browsed through the interface, and navigated by means of hyperlinks. This type of interlinking is another level of reading for which it is difficult to anticipate the reader's behaviour. On that level too, the editor's quest to direct the reader along to their own interpretation of the text can be as empowering as it can be restricting.

Last but not least, digital scholarly editions can also address computers - or at least those editions that provide access to their source code and enable text mining. As such, they facilitate distant reading as well as close reading.

How can we cater to all these different readers and forms of reading? That is the question this article tries to answer by building on its authors' experience with developing a digital edition called Briefe und Texte aus dem intellektuellen Berlin 1800-1830 (Baillot 2010b). This edition was developed in the context of a specific funding program, which meant that the project's funding phase could not exceed five years' time ${ }^{2}$ This limited time frame and funding resulted in a pragmatic approach to our editorial tasks, and influenced our workflow accordingly. Our primary goal was to aggregate resources that would answer a series of project-specific research questions (Baillot and Busch 2014). But of course, if answering these questions had been our sole aim, there would have been no need to develop a user-friendly interface for the data, nor to make these resources available in the form of an Open Access publication. The edition was hence conceived of as both a research environment for the research group in which it was situated, and as a scholarly edition that offers resources to the community at large. This in turn required to think more about how we would define such a "community at large": Who are the readers of a digital scholarly edition, what are their expectations, and to what extent should we make an effort to meet those expectations?

\section{A short tour through the digital edition Briefe und Texte aus dem intellektuellen Berlin 1800-1830}

The research group "Berlin Intellektuelle 1800-1830" at the department of Modern German Literature at the Humboldt-University of Berlin was dedicated to the analysis of intellectual relationships in Berlin around 1800. At that time, the Prussian capital was an eminent place of cultural transfer and knowledge exchange. Form and meaning of the participation of writers, publishers and scholars in public life defined the main research axis. To this end, the communication strategies these agents developed, as well as the close connections they

2 The project is described on Baillot et al. n.d. the scholarly contributions (publications, presentations) are listed in Baillot n.d. The project lasted from June 2010 to January 2016 and was hosted by the Institute of German Literature of the Humboldt-Universität zu Berlin. 
established between circles (such as between universities, academies, literary clubs and salons) were analysed on the basis of unpublished or only partially published manuscripts.

While letters constituted the main part of the edition's corpus, other sorts of texts such as draft manuscripts of literary texts or lecture notes are presented as well - this with the goal of cross-referencing the treatment of particular topics in different genres. The importance of letters in general as both a source of information and as a textual format with an inherent literary nature that adopts complex functions was one of the project's starting points. That is why the edition was called Briefe und Texte aus dem intellektuellen Berlin 1800-1830.

For the project, the research group designed four key questions to analyse the conditions and developments that were crucial for intellectual communication in Berlin between 1800 and 1830 as they were presented in these handwritten documents: 1) To what extent did the establishment of the Berlin University in 1810 contribute to the intellectual self-conception of scholars and academics who worked as lecturers?; 2) To what extent did the presence of the French in Berlin shape and define the political awareness of intellectuals?;3) Which communication strategies did male and female writers use to establish themselves in the literary milieu?; and 4) How can we extract political statements from a literary or scholarly corpus: ${ }^{3}$

A few months into the project, the research team decided to deviate from its initial plan to publish of a series of smaller print editions, and to development an overarching digital scholarly edition instead. To this end, the team reviewed several digital scholarly editions of letters that could serve as examples to follow. Great inspiration was drawn from "Vincent van Gogh. The Letters" (van Gogh 2009) and "Carl Maria von Weber - Collected Works (WeGA)" (von Weber 2017). In many ways, these editions helped the research group develop and implement their editorial practices. In addition to the best practices that were adopted by these digital editions, the editorial team implemented the standards recommended by the German Research Foundation (DFG), the project's funding agency for scholarly, web-based text publications (DFG 2015).

Not focusing on a single author, as most editions (even digital ones) do, the edition provides several possibilities to approach the manuscripts. This variety of options allows the user to access the edition in different ways, of which the one via the author-guided approach is just one alongside many. As such, the edited letters and texts can be accessed via their genre (letter, drama, novella, reports, lecture notes, etc.) or through a series of topics that are structured according to the team's four core research questions ${ }^{4}$

The standard view in the editorial interface shows a diplomatic transcription opposite a scan of the manuscript. These two columns on the screen can be

3 The complete list of research results (publications, papers, etc.) of the research group "Berlin Intellektuelle 1800-1830" can be found on Baillot n.d.

The complete editorial guidelines including all specifications for the different types of text genres can be found in German in Baillot 2010a 
reduced to a single one in just a click. For each column, it is possible to visualize the scan, two versions of the document's transcription (either as a diplomatic transcription of the document, or as an edited reading version of the text), the source code, the metadata, or the identified entities. It is also possible to generate a PDF of each document.

The diplomatic version provides a transcription of the manuscript's text with as little editorial interference as possible. All corrections, deletions and additions that are found in the manuscript are reproduced. Characteristics such as line breaks, the horizontal alignment of paragraphs, or abbreviations are all retained, and missing parts of the text are not reconstructed. Therefore, the diplomatic transcription is suited for textual analysis, interpretation, and investigating the text's genesis 5

In contrast to the diplomatic transcription, the reading text focuses on readability. While it still provides a reliable textual basis like the diplomatic transcription does, this version aims to present an easy-to-read view of the transcription that offers a quick point of reference. This is especially helpful when the document in question contains a lot of deletions and additions. In this view, the focus lies solely on the "basic text" in the author's hand - all other hands that might intervene in the manuscript (such as those of editors, recipients, or archivists) are omitted. Corrections, deletions and additions are tacitly integrated into the text, original line breaks are ignored, and abbreviations are written in full. Parts of the text that are missing but that the team was able to reconstruct with a high certainty are supplied in brackets. The text is also supplied with annotations, so as to address different editorial formats: on the one hand, these annotations reflect on the subtleties of the manuscript and the text; on the other, it offers details concerning the document's wider (and especially historical) context.

All six of these HTML views (and their downloadable PDF equivalents) are generated from the same TEI-XML file. Each TEI file contains the transcription of a single letter or manuscript, its markup and annotations, and its metadata. Additional information on various entities (persons, groups, places, and publications) are brought together in one TEI file per entity type, and connected to the text files via project-specific identification numbers. These TEI files are the basis for the metadata view, the listing of entities, and the indexation of entries. Each of these aspects are represented in the encoding of these elements.

All the different formats the project offers to visualize each text are also available to the reader for download and reuse under a CC-BY license. In addition, the reader has access to all of the project's relevant metadata, and to

5 Due to the time and funding constraints, the TEI encoding that was used in the project does not follow Critical Apparatus model (Consortium 2020a) - not even in the case of genetic phenomena. Instead, a project-specific encoding was developed that combines a light encoding of genetic phenomena in combination with named entities. A project-specific (not completely TEI-compatible) <hand $>$ element that refers to person entities allowed the team to connect both encoding levels (genetic and entity-based). The complete project-specific TEI encoding guidelines in English can be found in Baillot and Meyer 2016 
the indexed entries: this includes information on senders and addressees (in the case of letters); the manuscript's origin, provenance, and current holding repository; the editors that were involved, etc.

Overall, this edition is not radically different from the major current digital scholarly editions. What may set it apart, though, is that it is not focused on a specific author or genre, but rather on a historical context. Its qualities lie mostly in the presentation of manuscripts that are chosen because they are relevant to specific research questions, and in the combination of a series of features (be they structural, or on the level of the interface) that address these questions. Developed with four target audiences in mind (i.e. the research group itself; a broader scholarly audience; the community at large; and algorithms designed to harvest open data), the edition shows the potential digital scholarly editions have for opening up their data - as well as what some of the limitations of such openness can be. Is it even possible to develop an edition that would be as usable by a knowledgeable scholar as it would be by a computer?

\section{Editing for man or for machine?}

In general, scholarly (print) editions are developed by scholars, for scholars. This is especially true in the German context in which the Briefe und Texte edition was developed. Both the format and the price of such editions make it almost impossible to reach a wider audience. Knowing that one's edition will be primarily (and most of the time, exclusively) used by scholars who consult them in libraries, editors tend to design their editorial practices according to their own needs and habits.

Digital scholarly editions, on the other hand, are quite different from most print editions in terms of their accessibility. While some editions are passwordprotected or hidden behind a paywall, many of them are available in Libre Open Access (Suber 2012). This means that virtually everyone is able to access and use the digital scholarly edition. It does not mean that these editions will automatically have a significantly wider audience, nor that they were even developed with such a wider audience in mind. It does, however, change the premise of these editions, in the sense that they may afford editors with the possibility and legitimation to address such a wider audience. But does the simple fact that the editions are available actually make them "accessible" to that wider audience?

It is in fact more difficult to define the expectations of a non-scholarly audience than those of a scholarly audience. Trying to reach a wider audience is a business for which scholars are not properly trained. And what is more: this type of work is often unproductive in terms of career benefits - at least in the German academic context. On the contrary, a higher complexity is usually worth more in terms of academic reputation and capital than a greater accessibility of the research results would be. Hence, the aspiration to address a reader other than the editor's peers remains mostly unsupported by the academic system in terms 
of career evaluation, funding, and training.

Our decision to offer the user a reading version that is not presented as hierarchically inferior to any of the the other versions represented a major shift for the research team. What especially mattered during the development of this digital edition was that we would make all six visualizations equally easy to reach as the digital image of the manuscript. This included our decision not to transcribe the text at the sign level (e.g. by leaving some glyphs unrepresented), but instead to give readers the freedom to establish the connection between the digital image and the transcription by themselves (as mentioned in the introduction above). The hermeneutical relevance of this decision is obvious when one realizes its implications. It means that each reader can bring their own reading habits to the table. In spite of these varying preconditions, each reader should still able to make sense of the edition by themselves. This freedom is based on the assumption that the reader activates their own education and a critical thinking in the Kantian sense. In addition, this decision also has more political implications, since the documents that are displayed in the archives are not considered any less important or relevant than the transcriptions the editors (who are scholars) are presenting to the reader. This act of putting archival resources and scholarly interpretations on the same level is in itself already a statement. Finally, these decisions turned out to also have a direct influence on our choice of corpora, since not all archives would allow us to publish high quality digital images of their manuscripts in Libre Open Access.

These hermeneutical and, in a wider sense, political choices allowed us to present our edition as a tool that aims to enable readings of all sorts; to provide a structured space that empowers readers by giving them access to the text, and information to structure themselves. Of course, the reader is still directed, even in this setup - indeed, it would be delusional to think that it is possible to set up a "neutral" edition that allows for all possible readings. However, Briefe und Texte tries to offer its readers all the critical tools and elements they need to embark on an autonomous reading. The attempt to offer such an "enabling" edition (meaning: an edition that enables the reader to act as the designer of their own readings) is not new, but it does require us to take into account some specific aspects with regard to digital scholarly editions.

As editors we anticipate reading scenarios and use them as the basis for developing the edition's design, drawing mental maps of pathways that can lead the reader to the text. Here, those might include option such as: searching for a specific author, integrating data for a metadata aggregator, presenting connections as a network of persons ${ }^{6}$ etc. In the case of this edition, however, funding and time constraints limited our implementation of such reading paths. Taking the conditions in which the edition was produced into account, the result is overall satisfactory. But the edition is still not fully satisfactory when it comes to reader-friendliness. Our commitment to accommodate monitors of different

6 This has become the trademark of the Schlegel edition in the German-speaking area since Briefe und Texte was developped. 
sizes and resolutions, for instance, required us to fix some elements (especially frames) in a way that lacks fluidity. This means that some frame elements appear too dominant on the vast majority of monitors. This problem could not be overcome in this funding period.

The most straight-forward approach that a reader can take to discovering the contents of the edition, namely by finding the homepage and navigating down the tree structure of data from there, is a key area where editors can work on building a rapport with their readers. How do you grab and retain the reader's interest to do so? In general, editors are still in dire need of a set of standards that would give the kind of direction the scholarly book tradition would provide them with. To start, there are still no established (meaning: widely recognized and actually used) names for the different types of digital scholarly editions that exist, and that could contextualize the edition when the reader reaches its homepage. Most editions usually give themselves a name from the point of view of their subject, rather than from that of their method. From the onset, this forms an impediment to establishing a clear reading path for the reader.

But even if editors assumed correctly what the reader's first reaction to the homepage of their edition would be, it remains impossible for them to anticipate exactly how the reader will move on from there in all possible circumstances. It was only after a few years of development and daily usage that the editorial team of Briefe und Texte realized how unsuitable the edition's design (with its columns and additional information) is for actually reading the text. It is uncomfortable to read text in HTML, and even more uncomfortable when additional information pops up around it. The idea to offer a PDF version alongside the six different HTML displays and the query interface emerged from the diagnosis that the online edition in itself was not an adequate document for extensive reading. After making this realization, the team made sure that the reader could download a PDF version for each individual document, or for a whole corpus. As such, the edition's new PDF generator became a useful way for making the edition more readable.

More could yet be learned about our audience's reading habits through an analysis of the edition's log-files (as organized by Anna-Maria Sichani 2016). Such an analysis can be undertaken to find out how people understand and interact with Open Access policies by investigating, for example, how many users actually use the "Download XML" option that Briefe und Texte offers, or how many XML files are downloaded per user during a certain time frame. This research was inspired by Peter Boot's seminal study of the log-files of the Van Gogh edition (Boot 2011). His study mostly confirms well-known reading attitudes: namely that simple queries are used much more often than advanced queries; that links play a major role in the way the reader accesses information; etc. It was not easy, however, to extrapolate useful information from Boot's analysis of the Van Gogh Letters, and translate it into the context of our Briefe und Texte edition. In his study, Peter Boot demonstrated for example that the first and last letters that are presented on a web page are those that are consulted 
the most. Another major anchor point for the users in the case of the Van Gogh edition is to look for famous paintings. Based on these results, however the question remains how the findings can be used in an edition that does not revolve around a single author, or a single corpus - but that instead decidedly aims to deconstruct canonical approaches to the history of literature? The results of this analysis were certainly still useful, if only because of what it taught us about the possible expectations of the readers in general, and to answer questions such as: To what extent does the structural design of Briefe und Texte differ from that of other editions? Are there constants in the way readers approach editions, or does their approach strongly depend on the way the edition is designed, or even on the edited object? Is it possible to distinguish different reader types or reading patterns from one another, and if so, what can they tell us about the interest readers are giving to specific editions, or to editions in general? Although these questions may seem to deal solely with implementation issues, they are in fact representative of a major question regarding the relationship between the edited text and its reader, namely: Which role does the editor of a digital scholarly edition play in guiding the reader's interaction with the text? And how do we balance text with design?

At this point, it is important to reflect on the conceptualization of the relationship that is to be analysed here. "Reading" covers only part of the way text is accessed by the audience of a digital edition. In this case, the term "using" is in many ways more adequate to the multiplicity of approaches made possible by the digital media. Firstly, it can allow us to distinguish between linear reading (reading) and non-linear reading (navigating, for instance scrolling, as a relevant form of use). Secondly, it allows us to take design elements into account without necessarily contrasting them to textual elements. The following section will deploy a series of additional arguments for this approach to a (positive) understanding of the "use" of a digital scholarly edition.

\section{Accessing the edition from outside the edition}

In a digital scholarly edition such as Briefe und Texte, the reader's access to the text is enabled through different entry points (such as genres, authors, etc.), but also by the reader's queries (and their corresponding interfaces), and by the hyperlinks it establishes, both within the edition and outside of it. Each of these ways to access the text questions the concept of the "reader". Specifically in the case of correspondence editions, dedicated digital tools have also been developed to facilitate these different types of access to their text, and to offer readers a new level of user-friendliness.

The accessibility of the edition's data within Briefe und Texte - and the way it enables its use or re-use in terms of interoperability - is ensured by the implementation of authority files and standards such as: the Integrated Authority File (GND) for persons (Deutsche National Bibliothek 2016); GeoHack for places (MediaWiki 2020); XML and TEI for text encoding (Consortium 2020b); 
ISO standards (ISO n.d.); and by making the edition's source code available in Open Access ${ }^{7}$ In addition, it was also crucial to connect the edition with other repositories and editions, which we achieved in a first stage by implementing a GND BEACON (Wikipedia 2020). With this simple file format hosted by Wikipedia, it is possible to link content to one another based on their GND numbers. In the case of Briefe und Texte, we used this system to connect with historical agents. When a person appears in Letters and Texts (be it in edited texts, annotation, or metadata) that any other BEACON-using project records as well, the system will automatically provide a direct link to the respective page of this resource. In addition, the other way around, other resources using this technology will automatically be linked to our Briefe und Texte edition. The German National Library and many regional libraries, archives, biographical and bibliographical projects, and many others use the BEACON format. This makes it an easy way to connect the contents of digital resources with a wide range of scholarly web services.

Another way to access the information in Briefe und Texte, is at the document level. On this level, all the documents that are edited in Briefe und Texte are also listed in the national German database and national information system for collections of personal papers and handwritten manuscripts from German archives and institutions. This database is named Kalliope (http://kallio pe-verbund.info/de/index.html), and points each of these documents to the corresponding permanent URL in Briefe und Texte. This allows a user to browse through the repository of their favourite small archive looking for a specific letter, and from there to be guided to its facsimile, transcription, and annotation in Letters and Texts directly from the aggregated metadata in Kalliope. In addition, the editorial metadata in Briefe und Texte also includes links to Kalliope in the other direction, thereby guaranteeing reciprocity in the way the information is connected. Here, the efforts of cultural heritage institutions to catalogue and index data are joined with those of the scholarly editing and research communities, in an attempt to venture beyond the archival connection between image and metadata, and instead to include also edited transcriptions that are accessible straight from the archival catalogue through hyperlinks.

Finally, more advanced forms of access have been developed specifically for letters and correspondence since the start of our work on the Briefe und Texte edition. Letters offer particularly interesting opportunities for interconnecting textual data via the digital medium. One of the developers of Briefe und Texte, Sabine Seifert, is an active member of the TEI Special Interest Group Correspondence (SIG Correspondence). This group worked especially on correspondencespecific metadata within the TEI's <teiHeader> element working to generate more interoperable data, and to open TEI-encoded correspondences up to new,

$7 \quad$ The edition is licenced under a CC-BY 3.0 license for the editorial work. Each of the Cultural Heritage Institution that allowed us to reproduce scans of manuscripts specified their re-use conditions, which are mentioned below the relevant image. 
automated uses 8

With regard to encoding correspondence metadata, the SIG Correspondence proposed a new element called <correspDesc> (correspondence description) that contains core correspondence-specific information that is mentioned on letters or any other piece of correspondence. A more restricted form of the <correspDesc> element called the Correspondence Metadata Interchange (CMI) format was then developed to serve as the basis for even more standardized metadata exchange. To maximize its interoperability, CMI relies on authority files and standard formats so that it can still meet with the naturally diverse encoding methods of various letter-based editions and projects. The web service CorrespSearch harvests metadata of letters that are based on the CMI format and makes the correspondence-specific metadata of different German-language correspondence editions searchable with a single query (Dumont 2020), see also Dumont 2018). For an edition like Briefe und Texte, using the CMI framework and being integrated to the CorrespSearch platform provided us with an additional entry point at the document and author levels for each letter that is external to the edition itself. This represents one more way to attend and address different methods the user may employ to access the text and its context (metadata, annotation). In addition, it also offers the edition a way of making its contents available to computers, as the edition's standardized metadata become machinereadable. This is especially relevant in the case where integrating the GND Beacon, Kalliope, and CorrespSearch serves as a connection between different digital resources. It is easier to implement such connections on the level of metadata, as it is easier to standardize this type of data than it is to standardize text annotation. In return, these metadata then offer the user access to much deeper information in the form of the fully edited and annotated digital edition.

To conclude, we found that the best way to address the plurality of users is to break the edition down into different levels of granularity and units of text conceived as data and metadata, so as to present the user with a door into the editorial design of each of these levels that users with different interests are likely to open - be they archivists, scholars, avid letter readers, or even computers. The primary architecture designed for the Briefe und Texte edition answers a specific set of research questions. But it also leaves room - even taking its limited funding and time into account — for offering additional forms of access to users. So while there is one primary way of reading the text, the edition offers many alternative ways for the user to access it. As such, the Briefe und Texte edition offers an experimental step in the process of opening up our editions in a way that helps us to conceive of digital scholarly editions that move beyond the boundaries what print editions have to offer.

Anticipating multiple usability scenarios and implementing them in a digital edition offers us multiple ways to access the text. Of course, not even the edition presented here could perfectly anticipate all user requests, but at least it may

8 For the proposal on GitHub, see SIG 2019. in the TEI guidelines, see Consortium n.d. See also Stadler et al. 2016 
provide users with the necessary information to access the information they need by themselves. As such, the edition gives users something that a print version cannot, namely a user-generated and user-specific presentation of its materials. The resilience of an edition will always depend on how comprehensible its research results are - mainly in terms of the quality of its scans and the transparency of the editorial decisions that were made, but also by providing detailed links embedding the edition in a relatable scientific context. In a digital edition, any editorial uncertainties in the wording and syntactic or genetic classification of the edited material are immediately apparent. While this enables the user to make their own independent decisions while reading the edition, it also transfers a certain level of philological responsibility to the user. This democratization of the edition, facilitated by the digital medium, frees the edition from the ivory tower of philology, where it was allowed to blossom into its most specialized form for so long. Now, it is up to our users to exploit the new possibilities these digital scholarly editions have to offer.

\section{Bibliography}

BAillot, AnNe, 2010a. "Berliner Intellektuelle: Editorische Richtlinien." Available from: https://www.berliner-intellektuelle.eu/about?de (Accessed: 2020-07-28).

, 2010b. Briefe und Texte aus dem intellektuellen Berlin um 1800. Berlin: Humboldt-Universität zu Berlin. Available from: https ://www.berliner-intellektuelle.eu/ (Accessed: 2020-03-20).

— n.d. “Emmy Noether- Projekt / Projet Emmy Noether 'Berliner Intellektuelle 1800-1830' - Page professionnelle." Available from: http: //www .anne-baillot.eu/home-deutsch/forschung-de/intellektuellen (Accessed: 2020-03-23).

Baillot, Anne and Anna Busch, 2014. “'Berliner Intellektuelle um 1800' als Programm. Über Potential und Grenzen digitalen Edierens." Available from: https://literaturkritik.de/public/rezension.php?rez_id=19678 (Accessed: 2020-03-20).

Baillot, Anne, Anna Busch, Selma Jahnke, and Sabine Seifert, n.d. “Berliner Intellektuelle 1800-1830 — Institut für deutsche Literatur." Available from: https://www.literatur.hu-berlin.de/de/berliner-intellektuelle1800-1830 (Accessed: 2020-03-23).

Baillot, Anne and Alexander Meyer, February 2016. “Edition-specific TEI encoding guidelines. Nachwuchsgruppe Berliner Intellektuelle 1800-1830 Digital Edition group." Available from: https ://www.berliner-intellektuelle.eu/encoding-guidelines.pdf (Accessed: 2020-03-23). 
Boot, Peter, January 2011. "Reading Van Gogh online?" Ariadne (66).

Available from: http://www .ariadne.ac.uk/issue66/boot/ (Accessed: 2020-03-23).

Consortium, The TEI, February 2020a. "Critical Apparatus." Available from: https://www.tei-c.org/release/doc/tei-p5-doc/en/html/TC.html (Accessed: 2020-03-23).

, 2020b. TEI P5: Guidelines for Electronic Text Encoding and Interchange. Text Encoding Initiative Consortium. Available from: https://tei-c.org/release/doc/tei-p5-doc/en/Guidelines.pdf (Accessed: 2020-06-24).

, n.d. "TEI element correspDesc (correspondence description)." Available from: https://www.tei-c.org/release/doc/tei-p5-doc/en/ht ml/ref-correspDesc.html (Accessed: 2020-03-23).

Deutsche National BibliotheK, November 2016. "The Integrated Authority File (GND)." Available from: https://www.dnb.de/EN/Professionell/Standa rdisierung/GND/gnd_node.html (Accessed: 2020-03-23).

DFG, November 2015. “Informationen für Geistes- und Sozialwissenschaftler/innen. Förderkriterien für wissenschaftliche Editionen in der Literaturwissenschaft." Available from:

https://www.dfg.de/download/pdf/foerderung/grundlagen_dfg_foerd erung/informationen_fachwissenschaften/geisteswissenschaften/fo erderkriterien_editionen_literaturwissenschaft.pdf (Accessed: 2020-03-23).

Dumont, Stefan, 2018. “correspSearch - Connecting Scholarly Editions of Letters." Journal of the Text Encoding Initiative (10). doi: https://doi.org/10.4000/jtei.1742

— 2020. "correspSearch — Search scholarly editions of letters." Available from: https://correspsearch.net/index.xql (Accessed: 2020-07-28).

FranZini, Greta, 2016. "Catalogue of Digital Editions." Available from: https://github.com/gfranzini/digEds_cat (Accessed: 2020-03-23).

Ghelardi, Maurizio, ed., 2019. Burckhardtsource. Available from: https ://burckhardtsource.org/ (Accessed: 2020-03-23).

VAN Gogh, VIncent, 2009. Vincent van Gogh - The Letters, edited by Leo Jansen, Hans Luijten, and Nienke Bakker. Amsterdam \& The Hague: Van Gogh Museum \& Huygens ING. Available from: http://vangoghletters . org (Accessed: 2020-03-23). 
Grafton, Anthony, 2012. La page de l'Antiquité à l'ère du numérique. Paris: Hazan.

ISO, n.d. "Standards." Available from: https://www.iso.org/standards.html (Accessed: 2020-03-23).

Jung, Joseph, ed., 2015. Digitale Briefedition Alfred Escher. Zürich: Alfred Escher-Stiftung. Available from: https://briefedition.alfred-escher.ch/ (Accessed: 2020-03-23).

MediaWiki, 2020. “GeoHack." Available from: https://www.mediawiki.org/wiki/GeoHack (Accessed: 2020-03-23).

SAhle, Patrick, 2008. "A Catalog of Digital Scholarly Editions." Available from: https://www.digitale-edition.de (Accessed: 2020-03-23).

Schlegel, August Wilhelm, 2014. August Wilhelm Schlegel: Digitale Edition der Korrespondenz, edited by Jochen Strobel and Claudia Bamberg. Dresden, Marburg \& Trier. Available from: https://august-wilhelm-schlegel.de (Accessed: 2020-03-23).

Sichani, Anna-Maria, March 2016. "Beyond Open Access: (Re)use, Impact and the Ethos of Openness in Digital Editing." Available from: https://dixit. uni-koeln.de/wp-content/uploads/Sichani_Beyond-Open-Access.pdf (Accessed: 2020-03-23).

SIG, TEI Correspondence, April 2019. "correspDesc." Available from: https://github.com/TEI-Correspondence-SIG/correspDesc (Accessed: 2020-03-23).

Stadler, Peter, Marcel Illetschko, and Sabine Seifert, 2016. “Towards a Model for Encoding Correspondence in the TEI: Developing and Implementing $<$ correspDesc >." Journal of the Text Encoding Initiative (9). doi: https://doi.org/10.4000/jtei.1433

Suber, Peter, 2012. Open Access. Cambridge (MA): MIT Press.

von Weber, Carl Maria, 2017. Carl-Maria-von-Weber-Gesamtausgabe. Digitale Edition, edited by Gerhard Allroggen. Available from: https://weber-gesamtausgabe.de/A070002 (Accessed: 2020-03-23).

Wikipedia, 2020. "Wikipedia:BEACON." Available from: https://de.wikipedia.org/w/index . php?title=Wikipedia: BEACON\&oldid=202294152 (Accessed: 2020-03-23). 